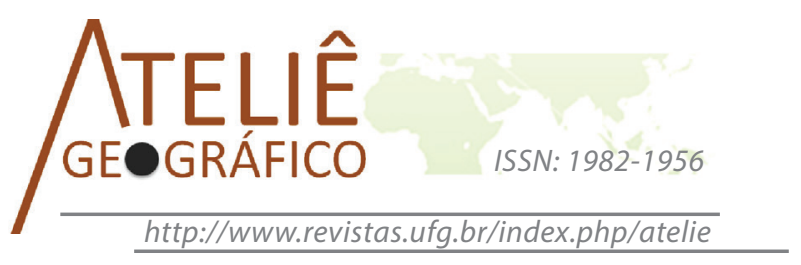

\title{
Imaginário e espacialidade vivida em narrativas quilombolas, Pimenteiras do Oeste - Rondônia, Brasil
}

\section{Imaginary and lived spatiality in quilombola narratives, Pimenteiras do Oeste-Rondônia, Brazil}

\section{Lo imaginario y la espacialidad vivida en las narrativas quilombolas, Pimenteiras do Oeste-Rondônia, Brasil}

\author{
Zairo Carlos da Silva Pinheiro
}

Universidade Federal de Rondônia - Campus Rolim de Moura

zairo.carlos@unir.br

\section{Cicilian Luiza Löwen Sahr}

Universidade Estadual de Ponta Grossa e Universidade Federal do Paraná cicilian@uol.com.br

\begin{abstract}
Resumo
Esse artigo busca discutir o imaginário na espacialidade vivida levando em conta a oralidade de sujeitos quilombolas. Para tanto, estuda-se o caso concreto de Pimenteiras do Oeste em Rondônia (RO) à luz das narrativas de seus quilombolas e também de teóricos da fenomenologia. Acredita-se que a reivindicação de um espaço quilombola, a Fazenda Santa Cruz, esteja sustentada tanto pelo imaginário social e pela espacialidade construída e reconstruída ao longo da história do grupo, como também - e principalmente - pelo imaginário social recente, tornado visível a partir da Constituição Federal de 1988. A pesquisa demonstra que a vontade de "ser quilombola" perpassa pelo imaginário de diferentes discursos, e que este imaginário se mescla com as espacialidades do grupo, tornando-os um dependente do outro.

Palavras Chave: imaginário; espacialidades; narrativas; quilombolas; Rondônia.
\end{abstract}

\begin{abstract}
This article is discussing the function of imaginaries in lived spatialities, based on an investigation on the orality of quilombolas. As such, it is directed towards a case study in Pimenteiras do Oeste in Rondonia (Brazil), a place which is understood through the narratives of its quilombola population as well as through phenomenological
\end{abstract}


methods. Its premises are that the claim for a quilombola space, in our case the Fazenda Santa Cruz, is based on a connection between social imaginary and its produced spatiality, on one hand grounded on a long-term lived experience of the group, and on the other referring to a more recent imaginary that is linked to the Federal Constitution of Brazil from 1988. Throughout the research it appears that the will to "be quilombola" is passing through the imaginary of several discourses, and that these imaginaries do mix within the lived spatialities of the group, turning each element dependent on the other.

Keywords: imaginary; spatiality; narratives; quilombolas; Rondonia.

\begin{abstract}
Resumen
El presente artículo discute lo imaginario en la espacialidad vivida a la luz de la oralidad de sujetos quilombolas (cimarrones). El caso de Pimenteiras do Oeste, Rondônia, es estudiado a partir de las narrativas de los quilombolas a través del análisis de la fenomenología. La demanda de un espacio quilombola, la Hacienda Santa Cruz, es apoyada tanto por el imaginario social y la espacialidad construida y reconstruida a lo largo de la historia del grupo, pero también - sobre todo - por el imaginario social reciente, que se hizo visible desde la Constitución Federal de 1988. La investigación muestra que el deseo de "ser quilombola" está presente en los diferentes discursos, y éste imaginario está mezclado además, con la espacialidad del grupo estudiado, haciéndolos interdependientes.

Palabras Clave: imaginario; espacialidad; narraciones; quilombolas (cimarrones); Rondônia.
\end{abstract}

\title{
Introdução
}

Se de um lado a relação dos homens em sociedade em muito contribui na formatação do imaginário, por outro, a espacialidade vivida e histórica se configura a partir do imaginário resultante dessa relação. Desta forma, simultaneamente à produção do espaço na vida cotidiana, constrói-se o imaginário subsidiado das relações nesse espaço.

Os discursos que integram a literatura em seu sentido lato - histórico, geográfico, estatal, de viagem e de narrativas dos sujeitos - representam maneiras de exprimir a vivência social. Assim, esse artigo tem como escopo discutir o imaginário na espacialidade vivida e experimentada levando em conta a oralidade de sujeitos quilombolas.

Nesse sentido, procura-se tematizar os discursos (do imaginário social) que são sugestivos para exprimir a base simbólica pela qual se torna possível, a um grupo de indivíduos, requerer "ser quilombola" a partir de sua "copertença" ao lugar. A questão central que se coloca é a compreensão da espacialidade (dos sujeitos) na sua dialética com imaginários focados e/ou desfocados do lugar. Trata-se, portanto, de tentar compreender

1. Esta noção de "copertença" a tomamos da obra de Mario Perniola (2009, p. 41), a qual é preferível por enriquecer o termo "pertencimento" tão comum nos trabalhos sobre comunidades tradicionais. Copertencimento aqui é o tornar-se ligado ao imaginário nas espacialidades que faz o ser quilombola ter sentido existencial. 
essa realidade do "ser quilombola" para além de um determinismo geográfico ${ }^{2}$, buscandose uma aproximação ao modo de pensar e sentir destes.

No caso concreto discutido aqui - o dos quilombolas de Pimenteiras do Oeste em Rondônia (Figura 01) - e de tantos outros de outras regiões do Brasil, acredita-se que a formação da Associação para a conquista da regularização fundiária seja sustentada por um tipo de imaginário social e pela espacialidade construída e reconstruída ao longo da história específica de cada grupo. Todavia, predomina o imaginário social recente e tornado visível a partir da Constituição Federal de 1988, em que os negros do Brasil são associados a uma vida de violência e sofrimento. ${ }^{3}$

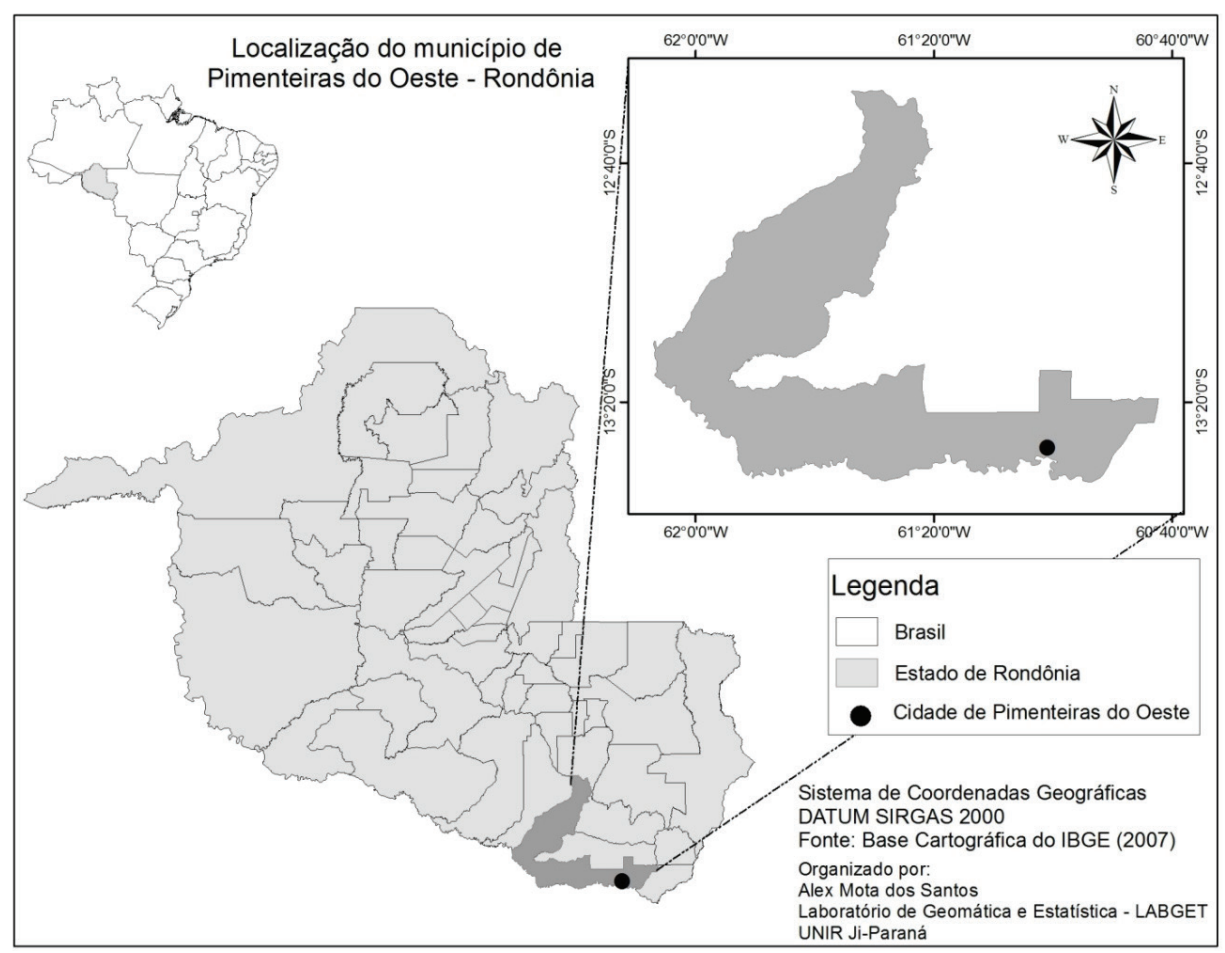

Figura 01 - Localização do município de Pimenteira do Oeste - RO.

2. A crítica ao "determinismo geográfico", no sentido de não se ater aos modos de sentir e de pensar, mas apenas ao lado descritivo do espaço geográfico, não é nova. O geógrafo francês Pierre Monbeig (1991), o qual realizou atividades de ensino e pesquisa no Brasil pelos anos 1930 e 1940, foi um dos precursores dela.

3. Tomasi, Löwen Sahr e Sahr em um artigo ainda inédito "O quilombo e suas 'transgressões' étnico-religiosas: um estudo de Geografia Social na perspectiva goffmaniana", submetido à Revista Geograficidades, também aprofundam tal questão, analisando a contradição entre o processo de ressemantização e as expressões culturais/ religiosas dos quilombolas. 
Assim, a pesquisa parte da suposição, aprofundada por Zairo Pinheiro (2014), de que as imagens sobre um passado de escravidão marcado pela "violência" e "sofrimento", na dialética com os sujeitos do presente, ajudam a formatar a base de sustentação de uma espacialidade prospectiva para a comunidade quilombola em estudo.

A partir dessa premissa, este artigo tem por base reflexões de teóricos da fenomenologia, bem como informações advindas de entrevistas realizadas com uso de metodologia da História Oral (ver MEIHY, 1996) junto aos sujeitos da comunidade quilombola de Pimenteiras do Oeste. O recorte empírico deste artigo são pessoas ${ }^{4}$ que viveram em alguma fase de suas vidas no antigo seringal Santa Cruz, lugar que é reivindicado como "território quilombola" através da ARQOS (Associação de Remanescentes Quilombolas de Pimenteiras do Oeste), constituída em 2010.

O município de Pimenteiras do Oeste foi criado em 1995 (Lei Estadual n. 645), tendo seu território desmembrado dos municípios de Cerejeiras e Cabixi. Localiza-se às margens do rio Guaporé, fronteira com a Bolívia, contando com 2.315 habitantes, destes $56 \%$ urbanos e $44 \%$ rurais. Mais de $60 \%$ das pessoas desse município são classificadas pelo Instituto Brasileiro de Geografia e Estatística como de cor preta ou parda. (IBGE, 2010).

A pesquisa in loco demonstra que a vontade de "ser quilombola" perpassa pelo imaginário (diversos discursos, e não só o dos sujeitos) que se mescla com as espacialidades vividas e experimentadas, tornando-os um dependente do outro. Ao salientar tais conceitos em conjunto (imaginário/espacialidade), pretende-se fazer compreensível que a atribuição de sentidos, símbolos e valores sugeridos aos espaços (plano simbólico) valoriza decisivamente à afirmatividade do espaço quilombola (plano empírico).

Para dar conta dessas questões, estruturou-se o texto em dois momentos. No primeiro, apontamos reflexões teórico-conceituais que nos auxiliam no entendimento da construção dialética do imaginário e da espacialidade vivida. No segundo, o foco é o imaginário nas espacialidades quilombolas, analisado nas narrativas dos sujeitos.

\section{A construção dialética entre o imaginário e a espacialidade}

É com filósofos e sociólogos do imaginário e do simbólico que este texto dialoga para a compreensão dessa categoria que chamamos de imaginário. Diz Bachelard (1990, p. 75) que: "O mundo real apaga-se de uma só vez, quando se vai viver na casa da lembrança". Pensa Bachelard aqui, no impulso "reconstrutor" do imaginário, que dá sentido ao ato de lembrar, que logo o preenche com o sentido que foge ao simples ato da realidade em que vive o sujeito que lembra.

Seu discípulo direto, Gilbert Durand (1998), mesmo sabendo que o imaginário não é uma "estância" do real, isto é, não há "o" imaginário aqui, e "o" real ali, procura definir as estruturas do imaginário por acreditar que o modo de existir do mundo ocidental

4. Foram entrevistadas oito pessoas, todavia, para este artigo foram selecionadas falas de apenas cinco delas. As "falas" foram destacadas em negrito no artigo, sempre indicando o nome e a idade de cada sujeito. 
as exige. Ao trilhar esse caminho, o autor chega a concluir que no ocidente houve um processo de iconoclasmo, isto é, uma tentativa (pois nunca se completou) de "combate" (a racionalidade foi um desses combatentes) ao "imaginário".

$\mathrm{Na}$ esteira de Durand aparece Michel Maffesoli (2001), para quem o imaginário é uma dialética entre o subjetivo e o objetivo, em que não se pode dizer aqui há a realidade sem o imaginário. Isso não quer dizer que haja "confusão" entre o real e o imaginário, entrementes, indica que para nosso mundo ocidental esta "separação" foi levada a sério (mesmo sem muita clareza) pelo nosso modo de pensar e viver numa dialética que separa os seus elementos para reuni-los permanentemente. Dessa forma, aquilo que chamamos de realidade (o "verdadeiro") tem muito de construção imaginária, de modo que o imaginário dialoga com a realidade (o "verdadeiro). Assim, amplia ou restringe os campos tidos como os mais verdadeiros como o econômico, o social ou o político pela sua função complementar. Para Maffesoli (2001), “o imaginário é uma força social, mas não quantificável”' (p. 75).

Juremir Silva (2003), articulando as contribuições de Maffesoli e Durand, salienta que: "Todo imaginário é real. Todo real é imaginário" (p. 7). Percebe-se que para Juremir, o imaginário é algo mais intrínseco do real. Isso se deve porque na sua releitura da obra de Maffesoli, Juremir absorve tanto o sentido de "imponderável" do imaginário quanto o "imponderável” que há da realidade. O que surge com isso é um mundo real que não se pode ser qualificado sem deixar de abrir o leque para o imaginário, que é força também neste jogo para formar os sentidos do mundo.

Nessa concepção, o imaginário não se diferenciaria muito das motivações de um poeta ou romancista, pois esses também são seres humanos fruto de vivências. Dizer que há um imaginário na poesia e dizer que não há imaginário na oralidade de qualquer pessoa é pensar algo paradoxal e absurdo. Seria negar a "presença" que é, pois, imaginária. Para Eliade (1996, p. 8): "O pensamento simbólico não é uma área exclusiva da criança, do poeta ou do desequilibrado: ele é substancial ao ser humano”.

Desta forma, os sujeitos quilombolas desta pesquisa, como veremos no segundo momento desse artigo, também projetam - através de suas narrativas - as imagens de um futuro melhor, as lembranças do antigo lar e suas posições políticas. Eles projetam o entusiasmo e as atitudes para responder as exigências do momento atual frente ao que a sociedade moderna organizada os apresenta através das leis, decretos e também da historiografia sobre a escravidão no Brasil. Todas essas imagens - fortemente midiatizadas - não somente se impõem aos sujeitos, mas também dialogam com ele.

Para o geógrafo Wolf-Dietrich Sahr (2007, p. 74), o imaginário não é nossa maneira apenas de "ver" o mundo, mas a integração da nossa visão à realidade materialmente vivenciada através das formas simbólicas. O simbólico é, assim, sua base de sustentação tanto ideal- como materialmente, mas sempre através do mundo vivido pelas pessoas. Apoiado-se em Ernst Cassirer, tem-se que o Agir (1994b, p. 187 e 2004, p. 268), ou seja, a concretização deste "símbolo" no empírico (1994a, p. 175), tornar-se o centro da filosofia cassirerana, transformando-o - diferentemente de outras teorias do símbolo - numa energia que ganha realidade sem separação entre significante e significado. O entendimento dado à palavra "espacialização", assim, se amplifica, como 
prenhe de multiplicidade espiritual sensível/insensível, visível/invisível, e porque não, exprimível/inexprimível, com os quais são "mediadas" as relações do homem consigo mesmo (corpo/mente) e com o ambiente "produzido" (endógeno/exógeno). ${ }^{5}$

Por isso, devemos perguntar para o "mundo" e não somente especular abstratamente sobre ele. Porém, compreender o mundo de uma maneira simplesmente empirista é cair no mesmo erro de alguém que o interpreta somente através do idealismo. Cada comunidade é seu próprio mundo porque não temos como apresentar um espaço humano, ex machina ${ }^{6}$, sem antes observar qual "visão de mundo" tal povo tem por referência e vive, ou o que apresentam materialmente no seu mundo.

Esse imaginário, quando refletido nas espacialidades vivenciadas e experimentadas, transforma o homem em "fazedor da História", e não apenas em "espectador da História", como a mídia e a historiografia (enquanto "verdades" únicas) nos deixam entender. As suas "vivências" - que só existiam enquanto subjetivo, ilusão e ficção no entender desta historiografia - passam a ser valorizadas, abandonando-se a ideia de que somente o que provém da história oficial e da mídia seja a realidade dos fatos. Assim, coadunamo-nos com Ecléa Bosi no sentido de que "A veracidade do narrador [no nosso caso, os quilombolas] não nos preocupou: com certeza seus erros e lapsos são menos graves em suas consequências que as omissões da história oficial" (1994, p. 37).

Optamos, assim, por compreender as espacialidades como frutos de "espaços vivenciados" (BOLLNOW, 2008; SCHMID, 2005), sobrecarregados de imagens, as quais passaram a formar uma materialização espacial quilombola diferenciada de uma comunidade para outra e/ou de uma região para outra. Desta forma, podemos reforçar que o espaço é imaginário, até mesmo porque não há nada que esteja fora do seu campo social (seja comunitário, tribal, social, estatal, religioso ou científico). Logo, tudo se torna "ponto de vista". Isto não quer dizer que elegemos as "vivências" como superiores a qualquer outra categoria, mas tão somente, que as vivências devem estar no mesmo nível de interesse que a escrita oficial. Elas são imaginárias porque são feitas na galáxia mitológica do convívio humano.

Nesse sentido, não há vivências isoladas e menos ainda, sem entrelaçamentos imaginários. A crença em um modo de vida puramente autóctone é ilusória. Para o historiador Alberto Lins Caldas, na esteira de Durand, "Cosmo não é uma ordem encontrada, mas uma ordem projetada nos processos de vivência e contravivência, é a formatação do caos, daquele existente que não podemos negar, mas que também não podemos saber". (CALDAS, 2001, p. 25, grifos do autor). Percebe-se, assim, como é difícil para a racionalidade ocidental associar o real ao imaginário.

Para os quilombolas de Pimenteiras do Oeste, a casa da lembrança é real como é real também a casa em que se mora "efetivamente". Seria então o espaço urbano de Pimenteiras, na qual mora a maioria desses sujeitos, não "aconchegante" para que eles quisessem voltar para a Santa Cruz rural dos antigos seringais? Nem sim, nem não, pois

5. Para outras interpretações desse geógrafo sobre o filósofo Ernst Cassirer, ver Sahr (2003 e 2007), cuja referencia completa encontra-se na relação final deste artigo.

6. Expressão latina derivada do grego que significa "Deus surgido da máquina", com o sentido de uma solução miraculoso, mirabolante, de um problema posto. 
o "passado", ou as "lembranças" do antigo lar, não são imagens vislumbradas somente para o que se viveu, mas sobretudo para o que ainda se poderia viver. Nessa oralidade há, portanto, a imagem de retorno ao "útero materno" (BACHELARD 1990, 2001; BOLLNOW, 2008), todavia, não como retroatividade, mas sim como prospectividade.

Para Bollnow (2008) o espaço vivenciado é humanizado e a vivência se encontra e se faz na espacialidade. O espaço, portanto, não é neutro, nem geométrico, e "a linguagem do geógrafo sem esforço transforma-se na do poeta" (DARDEL, 2011, p. 3). Assim, viver e agir no espaço, para o autor, é dizer que "criamos espaço em resistência, com o espaço” (p. 3), pois não há o espaço e o homem, mas o homem e o espaço.

A comunidade quilombola estudada apresenta esta ambivalência, pois em suas narrativas aparecem concepções diferenciadas de acordo com cada visão individual. Todavia, existe uma vontade comunitária de ser quilombola, mas, quando nos aproximamos dessa visão semelhante, que os indivíduos apresentam, observamos que o foco homogêneo se complica num mosaico de sentidos e imagens diferenciadas. Essas diferenciações são compreensíveis por estarmos realizando uma pesquisa em geografia humana e dentro da representação do mundo fenomênico, o qual nos apresenta sempre as ligações de fenômeno com fenômenos, não se tratando de filosofia pura, que visa à essência na existência do mundo.

O objetivo e o subjetivo estão, desta forma, ligados a essa concepção de espaço de Bollnow, na qual o espaço passa a ganhar sentido e a receber sentidos. $\mathrm{O}$ filósofo expressa: "esses significados não são devido a sentimentos apenas subjetivos que o homem liga ao espaço, mas são caracteres autênticos do próprio espaço vivido". (BOLLNOW, 2008, p. 18). Assim, a complexidade se apresenta justamente pelo fato de que "No fundo existem tantas geografias como sistemas culturais" (SAHR, 2007, p. 63).

O imaginário, que aqui se discute, indica uma espacialidade construída pelo homem: muda-se o homem, muda-se o espaço, e vice-versa. A espacialidade é, portanto, a existência feita carne, ou seja, pela presença desse homem, fundando seu espaço que nada mais é que ele mesmo. Assim, ao se falar de espaço já temos que ter em mente um espaço construído pelo homem. Tem-se, assim, que a espacialidade é algo essencial para a existência humana.

O homem não preenche "um” espaço, mas vive em relação “com” ele. Heidegger (2012, p. 155) demonstra isso ao escrever que "a espacialidade específica do próprio ente que vem ao encontro do mundo circundante, funda-se na mundanidade do mundo, e não o contrário". É a espacialidade enquanto ente (sujeito), numa relação visceral com o mundo ao redor que forma os espaços. Considerando isso, quando se observa um espaço já estamos olhando para uma espacialidade da "presença", sem a qual não existiria mundo ou, pelo menos, um mundo compreensivo. Nesse sentido, Bollnow (2008, p. 21) enfatiza: "O homem não se encontra no espaço como um objeto se encontra numa caixa, [...] a vida consiste originalmente nessa relação com o espaço e, portanto, nem mesmo em pensamento ela pode se libertar disso".

A espacialidade quilombola de Pimenteiras, portanto, é fruto de diferentes concepções de mundo em diálogo, numa dialética do endógeno e do exógeno. Não há um espaço quilombola no sentido material do termo, mas há um espaço vivido de 
(re)construção a partir dessas concepções de mundo, em que o espaço vivido torna-se um espaço quilombola. Há uma herança quilombola na linguagem oral desses sujeitos que será apresentada a seguir, buscando correlacionar o imaginário e a espacialidade quilombola de Pimenteiras do Oeste.

\section{O imaginário na (re)construção do "ser quilombola" e de suas espacialidades}

Busca-se a seguir sumariar os temas detectados a partir da análise da oralidade dos sujeitos quilombolas entrevistados no município rondoniense de Pimenteiras do Oeste. Todos os assuntos têm aqui, portanto, um caráter sugestivo do que se encontrou ao estudar a espacialidade complexa desses sujeitos e de quão heterogêneo caracterizase a formação do "ser quilombola", expresso na fala dos sujeitos sobre suas vivências e seus imaginários.

Observou-se em todos os sujeitos um sentido de topofilia, afetividade ao lugar. Porém, todo imaginário precisa de um centro motor, para que desse ponto possa adquirir sentido. A família é o epicentro do qual, para eles, tudo se iniciou e que fundamentou seu modo atual. Não importa para seu imaginário que tenham ouvido a informação repassada de forma aleatória, ou por outros meios que não sejam somente o familiar. "Os seres humanos, individualmente ou em grupos, tendem a perceber o mundo com o seu 'self', como o centro". (TUAN, 2012, p. 53). Esse sentido serve também para a cultura, pois todo povo (coeso e conquistador) vê o mundo a partir de si: o fenômeno do "eurocentrismo" nada mais é que a reprodução intrínseca desse velho ideal mítico; também os incas achavam que seu reino era o "centro do mundo" do mesmo modo.

A origem quilombola, que ajuda a formatar o "ser quilombola" aparece, por exemplo, para Seu Paulo não como uma herança pelo contar de histórias familiares, mas pela descendência direta quando diz que:

Descendo de pai e de mãe quilombolas ... e de meu vô ... vem do meu vô daí ... vem da minha mãe ... das duas vós por parte de mãe ... e meu vô por parte de mãe ... esse era de lá de Vila Bela ... que era um cativeiro mesmo ... meu vô. (PAULO, 73 anos).

Seu Paulo sente uma presença de sofrimento na vida dos negros que moravam em Vila Bela (hoje, município do norte do Mato Grosso). Não se sabe se essa ideia de sofrimento veio até ele pela família ou por escutar outros falares. Pouco importa aqui a origem do discurso, mas como esse discurso se torna realidade no presente, viabilizando que o "ser quilombola" desabroche nos sujeitos. Vila Bela para a história acadêmica não era um "cativeiro mesmo" como é para Seu Paulo. O imaginário se (re)constrói, à maneira que pode, a partir de seu modo existencial, sua espacialidade.

Martiniano José da Silva (2008, p. 163), pesquisando a escravidão do Brasil Central, aponta Vila Bela da Santíssima Trindade como um espaço que buscava frear o avanço espanhol e, como consequência, a escravidão ajudava na manutenção dessa ordem. Logo, o sofrimento em Vila Bela permaneceu no imaginário de Seu Paulo como um "cativeiro mesmo". 
O sujeito histórico é observado em Seu Hermelindo, onde o "ser quilombola", num primeiro momento de sua narrativa, aparece como uma espécie de desconhecimento, e em outro, como que justificado, tornando-se daí, conhecido e presencial. Ele comenta:

Com relação à herança quilombola de quando era criança ... não ouvia falar em quilombolas não ... nos antepassados ... Isso daí a gente nunca ouviu falar ... né? Até porque na época as pessoas trabalhavam e eu era muito ligado ao meu pai ... Tava trabalhando e num tinha tempo em dizer "eu vou passar pro meu filho esse tipo de assunto ...". (HERMELINDO, 66 anos).

A ausência de evidência de uma coisa, não significa a evidência da ausência, posto que, não saber que se era quilombola de fato, em um passado distante, não significa que não se é de direito, agora como remanescente. Assim, o sujeito histórico aqui, não aparece como desligado de uma "concepção de mundo", do imaginário. Há algo que o guia, que o impulsiona a buscar sua origem, sua história, que é o fundamento de sua espacialidade, uma espécie de busca por um centro inerente ao ser humano.

Para Bollnow (2008), essa busca por um elo se deve porque "o homem não pode viver apenas nesse mundo. Perderia sua estância se não tivesse nenhum ponto de referência fixo, ao qual todos seus caminhos são referidos, do qual partem, do qual retornam" (p. 133). O sujeito busca esse elo porque é próprio do homem essa busca pela sua origem histórica, para que seu ser possa adquirir, no presente, uma possibilidade de responder aos desafios postos no momento em que se vive.

Os sujeitos, todavia, são "novos", isto porque a comunidade é segmento político em si e seus integrantes acompanham o momento em que vivem, embora não deixem de ser imagem de algo antigo também. Não há pessoa alguma que não viva em função de perspectivas de futuro e que não queira melhorias para o ambiente em que mora. $\mathrm{O}$ imaginário do "novo" sujeito político procura essa ligação com o contemporâneo, mas ao mesmo tempo procura não desligar completamente do "tempo dos antigos", tempo em que se vivia um espírito comunitário.

Não haveria possibilidade do imaginário nacional, que incita a formação de comunidades quilombolas, ${ }^{7}$ se tornar real, sem encontrar sujeitos dispostos e ativos para efetivá-lo. Os sujeitos apresentam, no seu imaginário, uma predisposição para as diversidades e futuras conquistas a partir de sua postura política, inconscientemente ou não, adubada desde os "tempos antigos". Cada sujeito se forma, mesmo dentro do mesmo espaço, se adequando de maneira peculiar.

Podemos observar, da mesma maneira, o senso de organização política, mesmo que seja latente, até mesmo num homem como Seu Eulálio. Ele nunca se enveredou pela política, mas nem por isso deixou de ter uma perspectiva e de ver a importância da organização de seu grupo. Ele comenta que:

7. Pensa-se aqui nos diversos mecanismos legislativos que tornaram possíveis as comunidades se efetivarem enquanto comunidades tradicionais e quilombolas: o Decreto $\mathrm{n}^{\circ} 5.051$ sobre "populações tradicionais"; a Convenção no 169 de 1989, sobre os "Povos Indígenas e Tribais", da OIT (organização internacional do trabalho); os Artigos 215 e 216 da Constituição Federal (CF) e o Decreto nº 6.040, de 2004. 
É importante formar essa Associação de Quilombolas ... dizendo vamos tocar agora como se nós fôssemos descendente quilombolas ... é importante ... né? Se vir algum recurso pra gente ... pra mim ... Se vê ali em Pedras Negras ${ }^{8}$ ta funcionando ... por que só aqui não? Lá tem um cara que fez financiamento até de 15 mil reais ... fez financiamento pra comprar gado ... comprou motor ... tem prazos de pagamento ... com umas taxas com juros muito mínima ... é através dessa associação ... (EULÁLIO, 65 anos).

Ele sabe, como muitos outros, que possui origem em Vila Bela, portanto, deve "ser descendente de escravos", porém, percebe também, que isso não lhe diz nada enquanto "ser quilombola". Tornar-se quilombola é uma maneira de responder aos reclames do momento e organizar uma associação representa o caminho para se chegar a conquistas.

Nesse sentido, busca-se agora identificar as narrativas de (re)construção das espacialidades quilombolas a partir do imaginário do "indivíduo-coletivo". Sabe-se que não existem sujeitos sem uma sociedade ou um lugar para se viver e reproduzir. O estudo a partir do imaginário torna compreensiva a realidade dos sujeitos porque nos deixa em alerta tanto para o lado subjetivo quanto para o lado objetivo.

Há em qualquer sociedade dois tempos distintos ${ }^{9}$, mas também complementares. (CASTORIADIS, 2000). Estes são o tempo identitário, marcado pelo relógio, e o tempo imaginário, o da significação, em que os sujeitos dão as significações próprias ao seu modo de vida. Entretanto, o filósofo alerta para o fato de ambos serem inseparáveis, mesmo se mostrando divididos.

Dessa maneira, o imaginário social e vivido preenche e dá sentido a espacialidade. Esta, por sua vez, retribui o significado ao imaginário, tornando os sentidos visíveis nas falas dos sujeitos. Na verdade os sujeitos são "geógrafos" em potenciais porque dão nomes e são os que fazem sentido dialogando com o espaço em que vivem. Eles nos mostram uma geograficidade (DARDEL, 2011) ${ }^{10}$ ao se referirem sempre ao lugar enquanto solo amado, mas também, mostram-se aventureiros, porque, de certa forma, estão à procura de um caminho e maior oportunidade para se desenvolverem. Essa aventura pode ser simbolizada como a formação efetiva da "Associação dos Remanescentes Quilombolas de Pimenteiras do Oeste - ARQOS".

Tuan (2012), Bachelard (1990, 2001) e Dardel (2011) escrevem, mesmo em contextos diferentes, dos sentimentos do homem com o seu entorno, levando em conta o diálogo afetivo e existencial que travam com seu espaço. A (re)construção da espacialidade a partir do imaginário nos indica que há uma ligação existencial, e não abstrata, entre o homem e seu meio, no sentido em que Tuan (2012, p. 139) apresenta ao escrever que "O Turismo em uma utilidade social beneficia a economia, porém não une o homem à natureza". Quando o lugar não tem relação com o homem, este se torna estranho.

8. Comunidade quilombola também localizada no Vale do Guaporé em Rondônia, cuja Associação vem conquistando o atendimento de diversas demandas junto ao governo federal.

9. Para aprofundamento, ver Castoriadis (2000, p. 246).

10. Para aprofundamento, ver Dardel (2011, p. 1-2). 
Dona Alice em sua narrativa mostra seu primeiro contato com Pimenteiras do Oeste da seguinte maneira:

Vim para cá devido ao marido ... Ele passou aqui e viu o lugar ... O pai dele foi em Pedras Negras também ... Foi lá visitar nós e passou por aqui também e viu ... Meu sogro viu e convidou meu marido ... Meu sogro veio e morou lá em Santa Cruz porque não tinha Pimenteiras não estava aberto ... né? ... Ele foi lá em Santa Cruz e de lá escreveu para meu marido e mandou chamar ele ... (ALICE, 73 anos).

Segundo Dona Alice, "Vim para cá devido ao marido ... Ele passou aqui e viu o lugar ...", ou seja, ela não veio por conta própria, o marido a trouxe. Ela, portanto, não tinha nada a ver com o lugar: “... quando nós chegamos ali o meu marido tirou o lote porque nós descemos ali naquele porto ... nós viemos de barco ...”. Logo na sequência, ela aponta o sentido que teve a sua chegada, pela primeira vez, em Pimenteiras, e o desânimo que lhe tomou conta: "Não tinha ninguém ... ninguém ... ninguém! Gente do céu! Quando eu desci do barco ... que o barco subiu para Vila Bela da Santíssima Trindade e daí eu chorei heim ... depois que o barco deixou eu com três filhos ... ninguém morava mesmo ... aí eu me vi só ...”.

A sua maneira existencial, que prima pela família e o convívio social, e a visão do lugar desabitado tornou o lugar do desembarque em um espaço topofóbico (de desagrado). Quiçá se ela estivesse com seus familiares o lugar não teria sido tão desagradável assim. Todavia, somente "ver" algo não é fundamental. "Uma pessoa que", como alerta Tuan (2012, p. 28), "simplesmente 'vê' é um expectador, um observador, alguém que não está envolvido com a cena". Dona Alice se tivesse ficado somente no barranco, possivelmente teria achado a paisagem bonita, pois ela teria somente "visto". Mas, como ela agora se envolvia, então, ela adentrava e (re)criava o espaço vivido. Ela não estava ali como turista, mas como sujeito do lugar, o lugar agora era ela mesma.

Observa-se no decorrer desta seção que os sujeitos indicam lugares pelos quais têm lembranças como algo existencial. Os lugares que traçam seu itinerário com relação à herança quilombola são indicados, via de regra, apenas de “ouvir falar". Lugares onde seus antepassados estiveram ou mantiveram contato pelas histórias repassadas oralmente entres seus familiares.

O somente "ouvir falar", entretanto, não muda em nada a presença e a importância desses lugares para se entender a espacialidade histórica da comunidade. Da mesma maneira, os sujeitos ouviram falar de "escravos", dos "sofrimentos", e de que os mesmos "foram marcados a ferro". Não somente nossos sujeitos ouviram essas histórias, mesmo a maioria não tendo frequentado escola. Toda a história de escravidão, de sofrimento, mesmo tendo existido em um tempo e em lugar determinado, é um grande "ouvi falar" dos fatos escolhidos pelos historiadores que travaram conhecimento com o assunto.

Com relação à espacialidade histórica, aqui analisada, os sujeitos a imaginam e a (re)constroem a partir de um itinerário comum com origem na cidade de Vila Bela da Santíssima Trindade. A espacialidade, amiúde, é uma maneira de delimitar algo próprio, em que um grupo pode se reconhecer. Assim, de certa forma, podemos dizer que a 
comunidade quilombola de Pimenteiras do Oeste é símbolo de algo que acontece em outros lugares do país. A "busca de identidade"11 ou a "identidade própria" desenterra os antigos lugares. Assim, o antigo seringal de Santa Cruz (hoje fazenda Santa Cruz) aparece no itinerário dos sujeitos como identidade de chegada, lugar de acolhimento, no qual permanecerem por diversas gerações.

A maioria dos sujeitos quilombolas, entretanto, foi retirada de seu antigo lugar, a fazenda Santa Cruz, residindo atualmente na área urbana do Município de Pimenteiras do Oeste. Isso faz com que o grupo sinta necessidade de um "retorno", não mais como "antigamente", o que seria impraticável, mas enquanto novo e promissor desenvolvimento de conquista da modernidade. A espacialidade, nesse sentido, aparece dentro desse contexto de formar um caminho compartilhado e que seja o itinerário futuro de toda a comunidade (Figura 02).

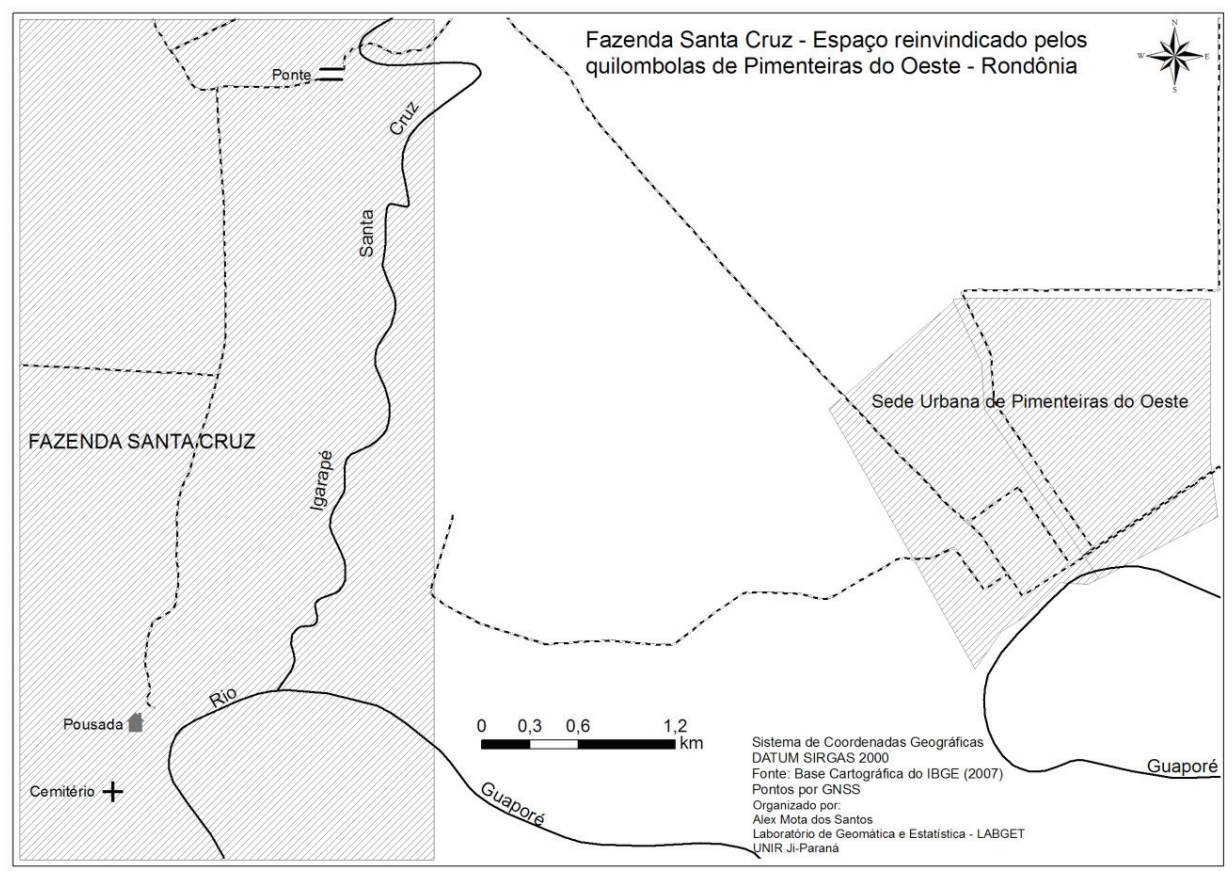

Figura 2 - Fazenda Santa Cruz

Essa espacialidade, tornada política, aparece justamente como desdobramento do protagonismo da comunidade organizada na ARQOS. O espaço sonhado e reivindicado passa a ser uma atualização, um "quadro" que somente o momento presente pode atuar

11. Para nós, "identidade" pode ser um "risco de ilusão", termo emprestado a Jean Starobinski (1974, p. 44). Os sujeitos quilombolas de Pimenteiras não "buscam uma identidade" justamente porque estão, pelo contrário, querendo as "conquistas" do entorno (sentido lato do termo). 
e conectá-lo, dando sentido às lembranças (BERGSON, 1990; MERLEAU-PONTY, 1999).

Seu Abel transmite-nos uma imagem confortante ao dizer:

Eu sonho entrando na mata ... cortando a seringa ... e eu sonho que quando eu acordo assim parece verdade ... Sonho que eu estou trabalhando ... aí eu acordo ... Então eu tenho aquele sonho porque eu gostei muito de trabalhar na seringa ... Fui criado na seringa e me criei e essa é a minha profissão ... (ABEL, 63 anos).

O narrador consegue sintetizar o prazer, a topofilia, de um lugar, de uma floresta que o faz sonhar.

Para uma pesquisa que visasse somente o lado econômico, este homem seria "alienado". ${ }^{12} \mathrm{O}$ materialista puro se perguntaria o que teria de sonho uma vida dentro da mata com poucos suprimentos. Esta constatação não quer dizer que estamos aqui a negar o lado sombrio de abandono pelos quais passaram os homens "lançados" nos confins da Amazônia, porém, uma visão somente de abandono e sofrimento não condiz com a totalidade da vida desses sujeitos.

Algumas indagações surgem: Por que Seu Abel não comentou algum sonho que teve aonde mora atualmente? Por que comentou justamente o sonho de uma casa onírica que não existe mais? Não temos dúvida, que é a partir desse sentimento pela sua casa onírica que ganha ou não sentido a atividade política que se desenvolve na atualidade na comunidade.

O seguinte trecho escrito por Bachelard mostra uma interpretação disso que estamos querendo dizer sobre a base simbólica de onde Seu Abel retira o conteúdo de sua espacialidade política. Diz o filósofo:

Sim, o que é mais real: a própria casa onde se dorme ou a casa para onde se vai, dormindo, fielmente sonhar? Eu não sonho em Paris, neste cubo geométrico, neste alvéolo de cimento, neste quarto com venezianas de ferro tão hostis à matéria noturna. Quando os sonhos me são propícios, vou para longe, numa casa da Champagne, ou nalgumas casas onde se condensam os mistérios da felicidade. [...] quando o sonho se apodera assim de nós, temos a impressão de habitar uma imagem. (BACHELARD, 1990, p. 76, grifo do autor).

A narrativa de Seu Abel é uma exceção, foi o único que falou, sem nossa solicitação, de um sonho de intimidade, em que se observa o quanto ainda tem muito do seu tempo no trabalho na floresta, que para ele é uma casa, agora de sonho, a qual não existe mais, mas que na forma de imagem, e isto é importante, visita-o de vez ou outra em seu sonho e o conforta.

Assim, a complexidade desse espaço quilombola se dá a partir de que, sendo complexo, é pois motivado por variados interesses pessoais e coletivos, tornando-o mais

12. Para esta questão, observar a análise de Morin (1997, p. 68 ss.), onde há uma discussão sobre a "alienação" sob a modernidade, em que essa "alienação" é mesmo vista, dentro das próprias conquistas do movimento operário de cunho materialista. 
que um simples espaço dado, mas espaço "mundanizado" (de sujeitos). O mundo é aqui entendido como o mundo dos sujeitos, a sua espacialidade política é o seu desvelamento e compreensão possível.

\section{Considerações Finais}

A dialética entre o imaginário e a espacialidade indica que tanto o mundo da mente (os sentidos) quanto o mundo material (espaço físico) formam as espacialidades humanas. É, portanto, a fricção entre pensamento e de realidade que une os dispersos para formar o "ser quilombola" da comunidade estudada. Bollnow (2008) ao expressar que "Cada modificação 'no' homem condiciona uma mudança de seu espaço vivido" (p. 18, grifo do autor) exprime justamente esta dialética, que foge ao homem, mas que também está nele. Esta mudança passa pelos contatos entre os níveis do significante (espaço físico) e do significado (imaginário social, ou mental).

Partindo dessa dialética, o artigo evidenciou que o lema moderno de valorização de remanescentes quilombolas, através dos mecanismos do Estado e de outras instituições (ONGs, Igrejas, Movimento Negro, etc.), é utilizado pelos sujeitos investigados como um suporte para se sentirem "em casa", como se um voltar às origens da quilombagem fosse uma "volta para um habitat" que não é tão harmonioso no presente. Esta estratégia utilizada permite que estes sejam "inseridos" na modernidade ("ser quilombola") como uma maneira de diálogo dentro do grupo e também com o seu entorno.

$\mathrm{Na}$ busca pelas espacialidades construídas pelo grupo e pelos indivíduos quilombolas de Pimenteiras do Oeste ao longo do percurso histórico vivenciado por eles, observou-se que o "ser quilombola" não é homogêneo e que as especificidades de sua espacialidade histórica (enquanto "história-pretexto") podem contribuir para uma possível (re)construção de sua espacialidade na atualidade. Nas "falas" dos sujeitos foram encontradas as possibilidades para se compreender o sentido do "ser quilombola" e da relação construída entre o imaginário e a espacialidade.

Até pouco tempo nenhum deles havia ouvido falar sobre serem descendentes de negros escravos, demonstrando este fato que, o importante não é tanto a história da herança geneticamente comprobatória, mas sim como o sujeito se sente e como ele se encontra no presente. Podemos entender que o presente, através da espacialidade e da oralidade, é o que "determina" o passado nesta configuração de ancestralidade de reminiscência quilombola.

Não há espaço vivido sem seus respectivos imaginários - midiáticos, historiográficos, estatais, geográficos, jurídicos e religiosos - que os componha e formate. Porém, estes não o fazem com "imposições" aos indivíduos. O fazem por mecanismos e maneiras diversas em que nunca se saberá exatamente se ambos não se "procuram" como complementos para novas maneiras de enfrentamento ao presente. O "ser quilombola", que estudamos aqui, é um ser ativo, que busca, estuda, ouve, fala e se interessa. Este "ser quilombola" é um "ser" de diversos humores que forma e é formado, praticando a dialética entre o imaginário e o vivenciado num processo de duplo condicinamento. 
Assim, as atividades do Estado que tentam preencher visões ideológicas (imaginários), se confrontam com (e não necessariamente seguem) os imaginários dos “quilombolas". Portanto, a desapropriação dessa imagem (em grande parte acadêmica) resulta numa reapropriação dialógica na vivência atual e futura dos sujeitos quilombolas.

\section{Referências}

BACHELARD, Gaston. A terra e os devaneios da vontade. São Paulo: Martins Fontes, 2001.

. A terra e os devaneios do repouso. São Paulo: Martins Fontes, 1990.

BERGSON, Henri. Matéria e memória. São Paulo: Martins Fontes, 1990.

BOLLNOW, Otto Friedrich. O homem e o espaço. Curitiba: Editora UFPR, 2008.

BOSI, Ecléa. Memória e sociedade: lembranças de velhos. São Paulo: Companhia das Letras, 1994.

CALDAS, Alberto Lins. Nas águas do texto: palavra, experiência e leitura em história oral. Porto Velho/RO: Edufro, 2001.

CASSIRER, Ernst. Wesen und Wirkung des Symbolbegriffs. Darmstadt:

Wissenschaftliche Buchgesellschaft: 1994a.

. Philosophie der symbolischen Formen. Darmstadt: Wissenschaftliche Buchgesellschaft, 1994b.

. A filosofia das Formas simbólicas. São Paulo: Martins Fontes, 2004.

CASTORIADIS, Cornelius. A instituição imaginária da sociedade. $5^{\mathrm{a}}$ ed., São Paulo: Paz e Terra, 2000.

DARDEL, Eric. O Homem e a Terra: natureza da realidade geográfica. São Paulo: Perspectiva, 2011.

DURAND, Gilbert. O imaginário: ensaio acerca das ciências e da filosofia da imagem. Rio de Janeiro: Difel, 1998.

ELIADE, Mircea. Imagens e símbolos. São Paulo: Martins Fontes, 1996.

HEIDEGGER, Martin. Ser e tempo. $7^{\mathrm{a}}$ ed., Petrópolis-RJ: Vozes, 2012.

IBGE - Instituto Brasileiro de Geografia e Estatística, 2010. http:/www.cidades.ibge. gov.br/xtras/perfil.php?lang=\&codmun $=110146 \&$ search=rondonia|pimenteiras-do-oeste Acesso em 02/03/2015.

MAFFESOLI, Michel. O imaginário é uma realidade (entrevista a Juremir Machado da Silva). Revista Famecos, mídia, cultura e tecnologia. Porto Alegre, v. 1, n. 15, p. 74-82, Ago. 2001. Disponível em: <http://revistaseletronicas.pucrs.br/ojs/index.php/ revistafamecos/article/view/3123/2395>. Acesso em: 26/09/2013.

MEIHY, José Carlos Sebe Bom. Manual de história oral. São Paulo: Loyola, 1996. 
MERLEAU-PONTY, Maurice. Fenomenologia da percepção. São Paulo: Martins Fontes, 1999.

MONBEIG, Pierre. Os modos de pensar na geografia humana. In: Boletim Paulista de Geografia. São Paulo: AGB, seção de São Paulo, n. 68, 1991. pp. 45-50.

MORIN, Edgar. Cultura de massas no século XX: Neurose. $9^{\text {a }}$ ed. Rio de Janeiro: Florense, 1997. (v. 1).

PINHEIRO, Zairo Carlos da Silva. O imaginário nas espacialidades: Quilombolas do Vale do Guaporé/Rondônia. 2014. Tese (Doutorado em Geografia) - Universidade Federal do Paraná, Curitiba.

PERNIOLA, Mario. Enigmas: egípcio, barroco e neobarroco na sociedade e na arte. Chapecó - SC: Argos, 2009.

RONDÔNIA. Lei no. 645, de 27 de dezembro de 1995. Cria o Município de Pimenteiras do Oeste.

SAHR, Wolf-Dietrich. Signos e espaço mundos - a semiótica da espacialização na geografia cultural. In: KOZEL, Salete; SILVA, Josué da Costa; GIL FILHO, Sylvio Fausto (orgs.). Da percepção e cognição à representação: reconstruções teóricas da geografia cultural e humanista. São Paulo: Terceira Margem, 2007. p. 57-79.

. Zeichen und RaumWELTEN - zur Geographie des Kulturellen. In:

Petermanns Geographische Mitteilungen, n. 2, p. 18-27, 2003.

SCHMID, Aloísio Leoni. A idéia de conforto: reflexões sobre o ambiente construído. Curitiba: Pacto Ambiental, 2005.

SILVA, Juremir Machado da. As tecnologias do imaginário. Porto Alegre: Sulina, 2003.

SILVA, Martiniano José da. Quilombos do Brasil Central: violência e resistência escrava. $2^{a}$ ed., Goiânia - GO: Kelps, 2008.

STAROBINSKI, Jean. As palavras sob as palavras: os anagramas de Ferdinan de Saussure. São Paulo: Perspectiva, 1974.

TUAN, Yi-fu. Topofilia. São Paulo: Difel, 2012.

Zairo Carlos da Silva Pinheiro

Professor Assistente do Departamento de História da Universidade Federal de Rondônia - UNIR, Campus de Rolim de Moura. Doutor em Geografia pela Universidade Federal do Paraná - UFPR.

Av. Norte Sul, nº 7.300, Nova Morada. 76940000 - Rolim de Moura, RO - Brasil. E-mail: zairo.carlos@unir.br 
Cicilian Luiza Löwen Sahr

Professora associada da Universidade Estadual de Ponta Grossa. Doutora em em Geografia Humana pela Universität Tübingen (Eberhard-Karls). Atuou como professora visitante na Universidade de Heidelberg (Ruprech-Karls) (2004), onde realizou também seu primeiro pós-doc. UEPG, Av. Carlos Cavalcanti, 3581, Uvaranas. 84030900 - Ponta Grossa, PR Brasil.

E-mail: cicilian@uol.com.br

Recebido para publicação em abril de 2015 Aprovado para publicação em junho de 2015 